UGC Approved Journal

IJIREEICE

\title{
Design of Aperture Coupled Microstrip Planar
}

\section{Array}

\author{
C.N. Sujatha ${ }^{1}$, N.S. Murti Sarma ${ }^{2}$ \\ Department of Electronics and Communications Engineering, Sreenidhi Institute of Science and Technology, \\ Yamnampet, Medchal, India ${ }^{1,2}$
}

\begin{abstract}
This paper describes the performance of the Aperture Coupled Microstrip Planar Array in C-band. The basic concept of aperture coupling is to achieve the wide frequency bandwidth \& low back radiation. The enhancement of the bandwidth in the present case is achieved by coupling to the microstrip antenna on one substrate from the microstrip line feed on another parallel substrate through an aperture in the ground plane, which separates the two substrates. A design procedure for aperture coupled microstrip antennas based on transmission line model is presented. The novel coaxial to microstrip line transition is devised and implemented to feed the aperture coupled microstrip antenna elements in planar array to achieve the wide impedance and pattern bandwidth. The experimental results of Return loss plot \& Radiation pattern for aperture coupled microstrip planar array antenna are presented.
\end{abstract}

Keywords: C-band, bandwidth, Back radiation, Microstrip antenna, Co-axial to microstripline transition, planar array, Aperture coupling, Return loss, Radiation pattern.

\section{INTRODUCTION}

Microstrip patches are attractive type of antennas due to their low cost, low profile, conformability and ease of manufacture. The aperture coupled configuration [1] also provides advantage of isolating spurious feed radiation by use of a common ground plane. The primary barrier in implementing these antennas in many applications, however, is their limited bandwidth-only on the order of a few percent for a typical patch radiator. (Fig.1)
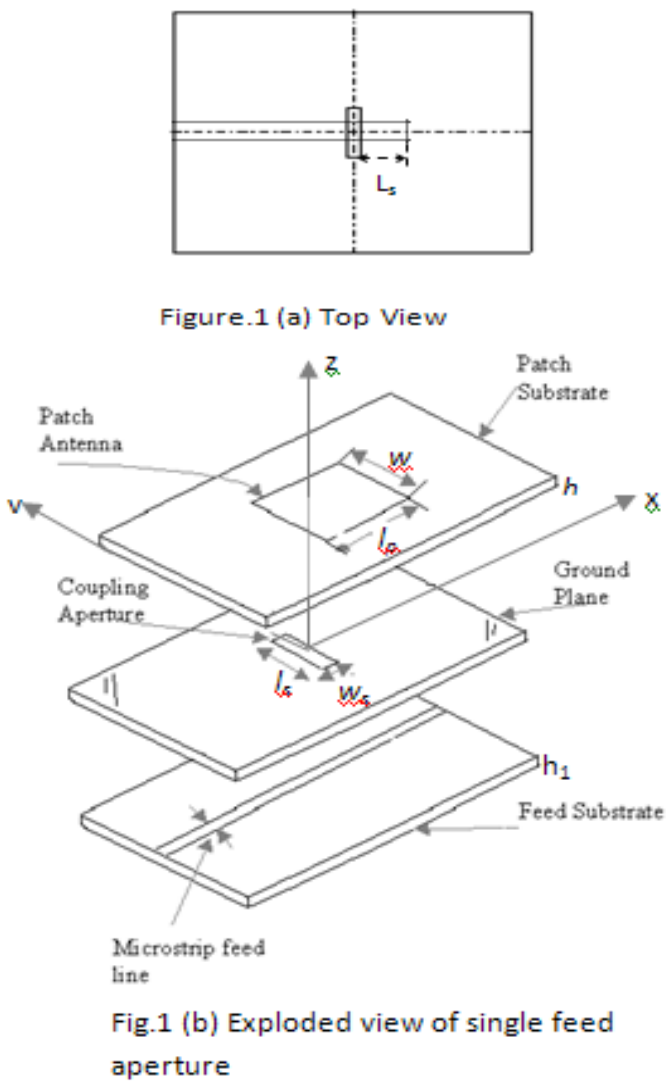


\section{ISO 3297:2007 Certified}

Vol. 5, Issue 6, June 2017

Because of this fact, much work has been devoted to increasing the bandwidth of microstrip patches. A straightforward method is to use a thick substrate with a low dielectric constant for the antenna; the bandwidths of around $10 \%$ can be achieved in this manner. Another technique which can be implemented in the aperture coupled configuration is to use a near-resonant aperture in combination with the thick antenna substrate, producing wide bandwidths [2].

The aperture coupled patch antennas have found widespread applications in communication systems during the last decade. They are also expected to be employed in radar systems, especially in the form of conformal arrays. Their most important advantage that makes them preferable from microstrip line or probe fed patches is the ability to use separate substrates for the feeding network and the patch itself. In their usual structure a patch printed on a low dielectric constant substrate (e.g. foam) is excited by an aperture in the ground plane which is in turn excited by a microstrip line printed on a separate substrate covering the other side of the ground plane. This configuration reduces the surface wave effects on the patch antenna, enhances its bandwidth, isolating the feeding line spurious radiation and leaves more space for the feeding network. This latter advantage makes them very attractive for phased arrays applications where phase shifters and/or power dividers must be incorporated in the feeding network. Moreover, modern frequency agile radars as well as electronic warfare applications require printed antennas with very large bandwidth, but these should also be of conformal nature.

The aperture coupled antennas could serve this need very well provided that a repeatable and relatively simple design procedure is first established for the both planar and atleast cylindrical substrate geometries. The present work is restricted to the planar geometry. The work on conformal aperture coupled antennas is quite limited and there are a lot of subjects that should be analyzed first, before moving to their design.

In this paper, design considerations for the antenna are discussed, and geometrical aspects of an experimental design are given. Theoretical and measured results for the experimental design are presented and compared.

Table-1: Optimised dimensions (mm)

\begin{tabular}{|c|c|c|c|c|c|}
\hline $\begin{array}{c}\text { Patch Width } \\
\left(\mathrm{w}_{\mathrm{p}}\right)\end{array}$ & $\begin{array}{c}\text { Patch Length } \\
\left(\mathrm{l}_{\mathrm{p}}\right)\end{array}$ & $\begin{array}{c}\text { Slot Width } \\
\left(\mathrm{w}_{\mathrm{s}}\right)\end{array}$ & $\begin{array}{c}\text { Slot Length } \\
\left(\mathrm{l}_{\mathrm{s}}\right)\end{array}$ & $\begin{array}{c}\text { Stub Length } \\
\left(\mathrm{L}_{\mathrm{s}}\right)\end{array}$ & $\begin{array}{c}\text { feed width } \\
\left(\mathrm{w}_{\mathrm{f}}\right)\end{array}$ \\
\hline 16.9408 & 13.4553 & 1.0 & 12 & 6.72 & 2.4649 \\
\hline
\end{tabular}

\section{DESIGN AND DEVELOPMENT OF ARRAY}

Using the above design formulae and factors outlined in App.A, B, a microstrip aperture coupled antenna designed and experimentally optimized with dimensions given in Table 1 . The measured electrical performance of the antenna is given in Table-2.

Table2: Electrical performance of antenna

\begin{tabular}{|c|c|c|c|c|c|}
\hline Antenna Configuration & Impedance Bandwidth (10dB & \multicolumn{2}{l|}{ HPBW (degrees) } & \multicolumn{2}{l|}{ Gain( dB) } \\
\cline { 3 - 6 } & Return loss) in GHz & Theoretical & Practical & Theoretical & Practical \\
\hline Single Element & 8 & 80 & 74 & 6 & 4 \\
\hline 4x4 Planar Array & 8 & 24.6 & 25 & 16.7 & 13.7 \\
\hline
\end{tabular}

The specified gain and Beam width for the microstrip antenna cannot be achieved by using a single radiating element and there is a need for going to array configuration. The required beam widths and gain can be obtained by using a planar array structure. The finalized single element is used for the design of $2 \times 2$ planar array. The corporate feed structure is selected as the array feed. The feed structure for the array consists of feed lines having different widths depending on the impedance value.

Quarter wave transformers are used for impedance transformation, which is necessary for achieving good impedance match. Since the source impedance is of 50-ohms, the feed line should have the same characteristic impedance.

The four-element sub array forms the basic building block for the entire array. The four elements are arranged in a $2 \times 2$ square grid configuration with element spacing $0.85 \lambda_{0}\left(\lambda_{0}\right.$ free space wavelength). The aperture size of the $2 \times 2$ planar array is $38 \mathrm{~mm} \times 41.5 \mathrm{~mm}$. 
UGC Approved Journal

IJIREEICE

\section{A. Planar Array of dimension $4 \times 4$}

To achieve the required gain of $16.7 \mathrm{~dB}$, a $4 \times 4$ planar array with aperture dimensions of $87.13 \mathrm{~mm} \times 90.62 \mathrm{~mm}$ shown in Fig. 2 has been designed using the $2 \times 2$ planar array as the basic building block. To minimize the insertion loss the parallel/series feed method is employed where all the 4-element sub arrays are combined in parallel, as well as in series, by the feed network of planar array. This is supported with a result in Fig.7.

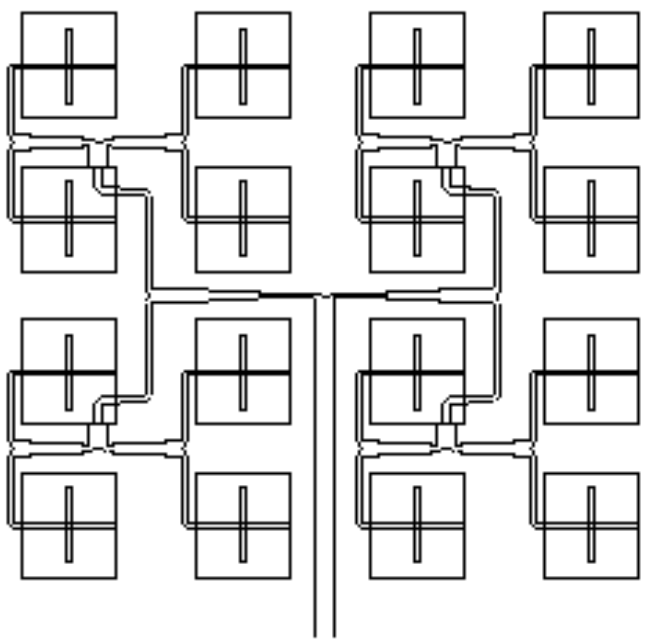

Figure 2 Layout of Microstrip 4x4 Planar Array

\section{EXPERIMENTAL RESULTS AND DISCUSSION}

The optimized single element is used for constructing the final $4 \times 4$ planar array. These elements are arranged into $2 \times 2$ sub array forming the basic building block. A 4x4 array has been fabricated on RT Duroid 5880 substrate of 62 mil $(1.6 \mathrm{~mm})$ thick using photolithographic technique and a coaxial SMA connector is used to excite the array. The novel coaxial to microstrip line transition is devised and implemented for feeding the planar array to achieve the broad band performance over 4-12 GHz. A cavity with internal walls covered with microwave absorber is used to suppress the stray radiations from the feed lines to reduce the back radiation. Obtained results for the single element and $4 \times 4$ planar array are given in Table-2. The measured swept frequency Return loss (VSWR) plot of the 4x4 planar array is shown in Fig. 3. The plot show continous decrease of return loss as frequency is progressed from 3 to $15 \mathrm{GHz}$. The measured radiation pattern in elevation plane at $4 \mathrm{GHz}, 7 \mathrm{GHz}$ and $12 \mathrm{GHz}$ are shown in Fig. 4.-6 The patterns were drawn in the anechoic chamber of DLRL[6]. The patterns are directly presentd along with the grid. The patterns are of normalized type whose peak value is shown at zero degree as per usual measurement convention. The Photographs of the experimental $4 \times 4$ planar array fabricated according to design is shown in Fig. 7

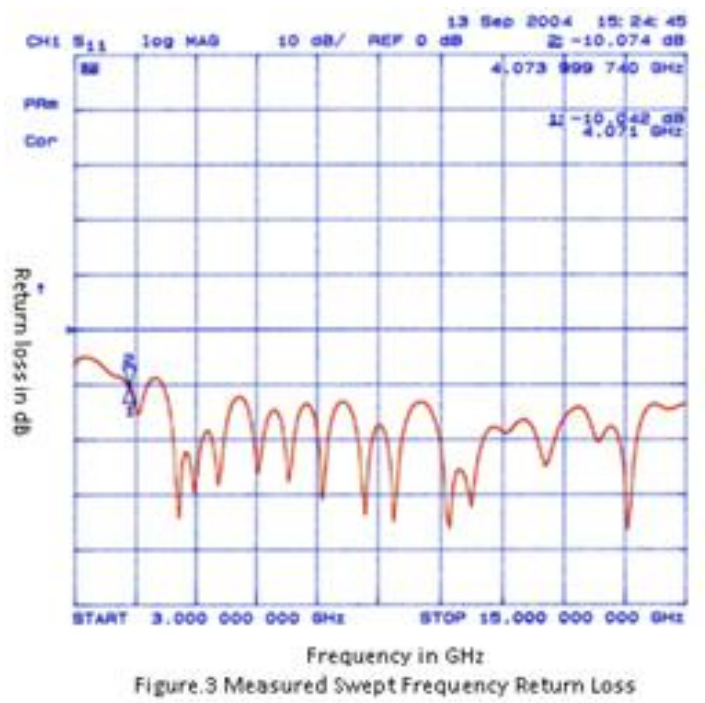




\section{International Journal of Innovative Research in Electrical, Electronics, Instrumentation and Control Engineering}

\section{ISO 3297:2007 Certified}

Vol. 5, Issue 6, June 2017

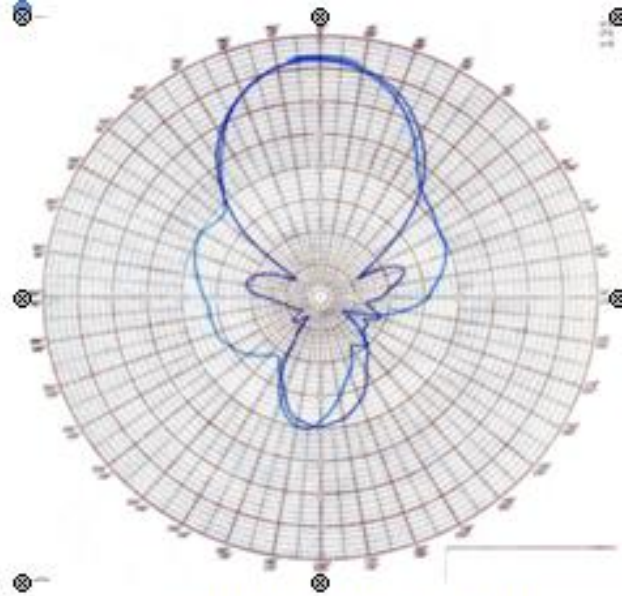

Figure4 Radiation Pattern $(4 \mathrm{GHz})$

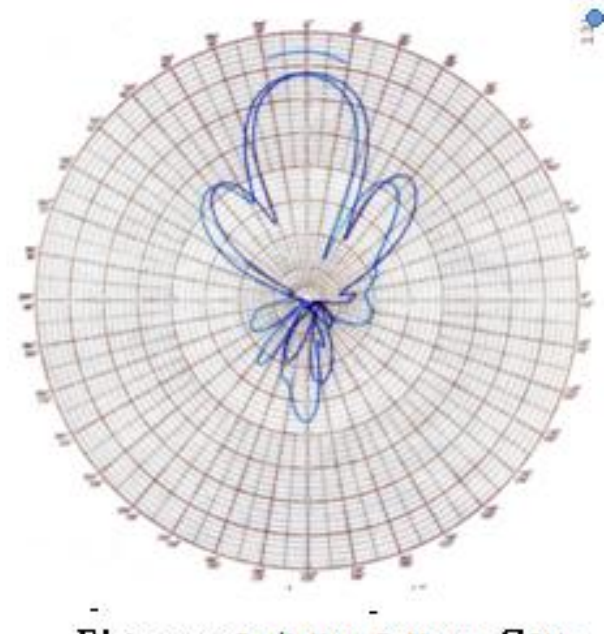

Figure 5 Radiation Pattern $7 \mathrm{GHz}$

From above patterns Higher frequency is generating several side lobes that requires focus. Of course the main beam is appreciably sharper at high frequency. But this side lobe level of main lobe is appreaciably smaller 4 and moderate at 7 $\mathrm{GHz}$ This sharpness is with raise of operating frequency from 4 to $12 \mathrm{GHz}$.

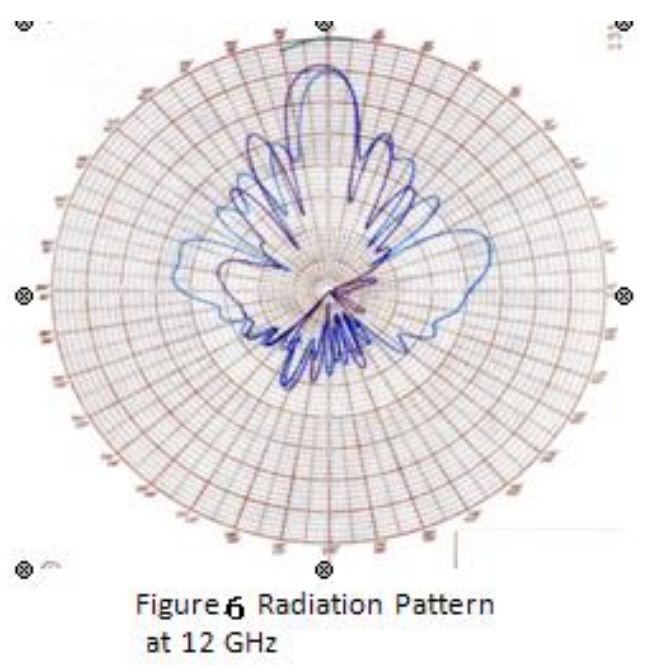

If peak sharpness is the criteria than sharpnes, this pattern will be practiced with a smart antenna technology and it have appreacibe resolution. The Final design also appears with large aperture area that may be compatible with antenns like dish etc. The feed location is appears to be central feed.

\section{CONCLUSIONS}

A microstrip planar array using aperture coupled radiating element has been designed and developed for communication application. Design of the antenna is simplified by developing computer programs using MATLAB software. The design of single element aperture coupled microstrip antenna is finalized and the desired results are obtained. Software programs have been developed in MATLAB for obtaining the microstrip antenna dimensions and the coordinates of the patch (used for fabrication purpose). These programs can be used for obtaining the coordinates at any desired frequency.

Using this finalized single antenna as basic radiating element a microstrip planar array has been successfully developed in C-band. The design of 4x4 planar arrays greatly improved the gain and decreases the Beam Width. The measured beam width and gain has good agreement with predicted theoretical values. Cavity walls lined with absorbing material and novel coaxial to microstrip line transition for excitation helped in achieving broadband performance. Thicker substrate results in wider bandwidth, but less coupling for a given aperture size. 
UGC Approved Journal

IJIREEICE

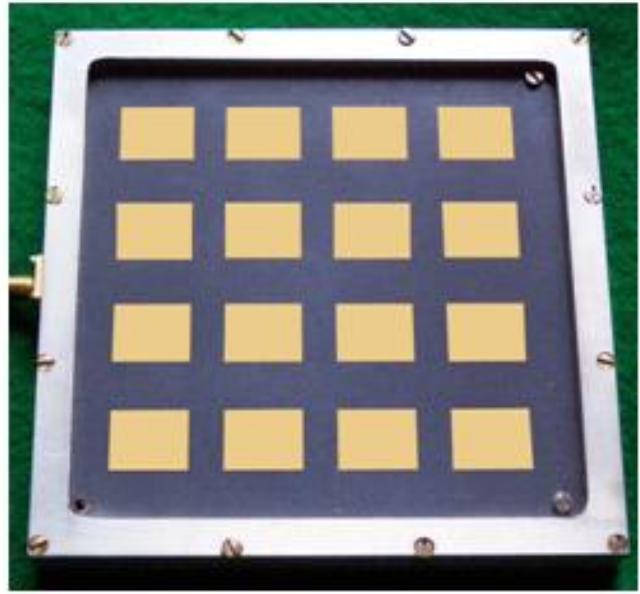

Figure 7 Photograph of

$4 \times 4$ Planar Array

\begin{abstract}
Appendix-A
Geometry of the Antenna

The geometry of the aperture coupled microstrip patch is shown in Fig.1, along with the dimensions of the wideband configuration. The variations of the following parameters effects the characteristics of Aperture coupled microstrip antenna [3]:
\end{abstract}

Antenna substrate dielectric constant $\left(\varepsilon_{r}\right)$ : This primarily affects the bandwidth and radiation efficiency of the antenna, with lower permittivity giving wider impedance bandwidth and reduced surface wave excitation.

Microstrip patch width $\left(w_{p}\right)$ : The width of the patch affects the resonant resistance of the antenna, with a wider patch giving a lower resistance. Square patches may result in the generation of high cross polarization levels, and thus should be avoided unless dual or circular polarization is required.

Feed substrate dielectric constant $\left(\varepsilon_{r f}\right)$ : This should be selected for good microstrip circuit qualities, typically in the range of 2 to 10 .

Feed substrate thickness $\left(h_{1}\right)$ : Thinner microstrip substrates result in less spurious radiation from feed lines, but higher loss, a compromise of $0.01 \lambda$ to $0.02 \lambda$ is usually good.

Antenna substrate thickness $(h)$ : Substrate thickness affects bandwidth and coupling level. A Microstrip patch length $\left(l_{p}\right):$ The length of the patch radiator determines the resonant frequency of the antenna.

Slot length $\left(l_{s}\right)$ : The length of the coupling slot primarily determines the coupling level and back radiation. The slot should therefore be made no longer than is required for impedance matching.

Slot width $\left(w_{s}\right)$ : The width of the slot also affects the coupling level, but to a much less degree than the slot length. The ratio of slot width to length is typically $1 / 10$.

Feed line width $\left(w_{f}\right)$

Besides controlling the characteristic impedance of the feed line, the width of the feed line affects the coupling to the slot. To a certain degree, thinner feed lines couple more strongly to the slot.

\title{
Feed line position relative to slot
}

For maximum coupling, the feed line should be positioned at right angles to the center of the slot. Skewing the feed line from the slot and positioning the feed line towards the edge of the slot will reduce the coupling. 


\section{Position of the patch relative to the slot}

For maximum coupling, the patch should be centered over the slot. Moving the patch relative to the slot in the H-plane direction has little effect, while moving the patch relative to the slot in the E-plane (resonant) direction will decrease the coupling level.

\section{Length of tuning stub $\left(\mathrm{L}_{\mathrm{s}}\right)$}

The tuning stub is used to tune the excess reactance of the slot coupled antenna. The stub is typically slightly less than $\lambda_{\mathrm{g}} / 4$ in length; shortening the stub will move the impedance locus in the capacitive direction on the smith chart.

The antenna excitation, or equivalently the coupling between the microstrip line and the slot and between the slot and the patch given in [4]. The two coupling mechanisms are very similar, since the patch can be considered as an openended wide microstrip line. For maximum coupling between the slot and the patch, the slot should be rectangular and positioned parallel to the two radiating edges along their mid-distance (e.g. along $\mathrm{x}=0$ in Fig. 1).

\section{Appendix-B: Design Formulae.}

Single Element design is as follows.Design involves the determination of the width $\left(\mathrm{w}_{\mathrm{p}}\right)$ and the length $\left(\mathrm{l}_{\mathrm{p}}\right)$ of the patch from the knowledge of the resonant frequency, $\mathrm{f}_{\mathrm{r}}$ (in $\mathrm{Hz}$ ), thickness of the substrate, $\mathrm{h}$ (in $\mathrm{mm}$ ), and the dielectric constant, $\varepsilon_{\mathrm{r}}$

\section{i. Patch Width $\left(w_{p}\right)$}

For an efficient radiator, a practical width that leads to good radiation efficiencies [4] is

$w_{p}=\frac{\mathrm{c}}{2 f_{r}}\left(\frac{\varepsilon_{\mathrm{r}}+1}{2}\right)^{\frac{-1}{2}}$

where, $\mathrm{c}$ is the velocity of light in free space.

\section{ii. Patch Length $\left(\mathbf{l}_{\mathrm{p}}\right)$}

a) The effective dielectric constant of the microstrip antenna may be determined [4] using

$$
\varepsilon_{\text {eff }}=\frac{\varepsilon_{\mathrm{r}}+1}{2}+\frac{\varepsilon_{\mathrm{r}}-1}{2}\left(1+\frac{12 \mathrm{~h}}{w_{p}}\right)^{\frac{-1}{2}}
$$

b) Once $\mathrm{w}_{\mathrm{p}}$ is found, the extension of the length $\Delta \mathrm{l}$ (due to fringing effect) is determined [4] using

$$
\left[\frac{\Delta \mathrm{l}}{\mathrm{h}}=0.412 \frac{\left(\varepsilon_{\mathrm{eff}}+0.3\right)\left(\frac{w_{p}}{\mathrm{~h}}+0.264\right)}{\left(\varepsilon_{\mathrm{eff}}-0.258\right)\left(\frac{{ }^{w} p}{\mathrm{~h}}+0.8\right)}\right]
$$

c) The actual length of the patch can now be determined by

$$
l_{p}=\frac{\mathrm{c}}{2 f_{r} \sqrt{\varepsilon_{\text {eff }}}}-2 \Delta \mathrm{l}
$$

The calculated dimensions of the antenna element using the above equations are

$$
\begin{gathered}
\mathrm{W}_{\mathrm{p}}=16.9408 \mathrm{~mm} \\
\mathrm{l}_{\mathrm{p}}=13.4553 \mathrm{~mm}
\end{gathered}
$$

\section{iii. Slot Length $\left(\mathbf{l}_{\mathrm{s}}\right)$}

The aperture coupling technique is used to feed the microstrip patch antenna. For maximum coupling between the slot and patch, it is required that the slot should be rectangular and positioned parallel to the two radiating edges of the patch along their mid distances. Concerning the coupling between the microstrip line and the aperture, it is required that the slot should be perpendicular to the feed line and its width should be small enough to have minimum perturbations to the feed line fields. Also the slot length should be long enough to avoid the interactions between the feed line fields and the slot edges. The slot length is calculated using the in equation [5] $l_{s}>w_{f}+n . h_{1}$ with $n>6(B .5)$

Where $\mathrm{w}_{\mathrm{f}}$ is Feed line width $(\mathrm{mm})$ and $\mathrm{h}_{1}$ is its substrate thickness $(\mathrm{mm})$. Using this equation the slot length $\left(1_{\mathrm{s}}\right)$ is calculated as $12 \mathrm{~mm}$ for the given parameters of substrate with a set of $\mathrm{n}$ at 14 . 
UGC Approved Journal

IJIREEICE

\section{International Journal of Innovative Research in} Electrical, Electronics, Instrumentation and Control Engineering

\section{ISO 3297:2007 Certified}

Vol. 5, Issue 6, June 2017

iv. Slot width $\left(\mathbf{w}_{\mathrm{s}}\right)$

As a rule of Thumb [5], the ratio between slot width over its slot length is given by

$$
\frac{w_{s}}{l_{s}}=\frac{1}{10}
$$

The slot width according to the above equation is $1.2 \mathrm{~mm}$. As slot width increases, the back radiation increases. In order to keep the back radiation to minimum, the slot width is experimentally optimised as $1.0 \mathrm{~mm}$.

\section{v. Stub length $\left(\mathbf{L}_{\mathrm{s}}\right)$}

The stub length is (Fig.1 (a)) selected on the basis of impedance matching considerations. For better impedance matching over broad frequency bandwidth, the stub length should be slightly less than $\lambda_{\mathrm{g}} / 4$ or $1_{\mathrm{p}} / 2$ [3]. Hence a stub length of $6.72 \mathrm{~mm}$ is selected for the present application.

\section{vi. Microstrip line width $\left(\mathrm{w}_{\mathrm{f}}\right)$}

The width to height ratio of the microstrip for the given dielectric material is calculated using following equations [4].

$$
\begin{aligned}
& \frac{w_{f}}{h_{1}}=\frac{8 \mathrm{e}^{\mathrm{A}}}{\mathrm{e}^{2 \mathrm{~A}}-2} \cdots . . \mathrm{A} \leq 1.52 \\
& \left.\frac{w_{f}}{h_{1}}=\frac{2}{\pi}\left[\begin{array}{l}
B-1-\ln (2 B-1)+. . \\
\frac{\varepsilon_{\mathrm{r}}-1}{2 \varepsilon_{\mathrm{r}}}\left\{\ln (B-1)+0.39-\frac{0.61}{\varepsilon_{\mathrm{r}}}\right.
\end{array}\right\}\right] \cdots \mathrm{A} \succ 1.52 \\
& A=\frac{z}{60} \sqrt{\left(\frac{\left(\varepsilon_{\mathrm{r}}+1\right)}{2}\right)}+\frac{\varepsilon_{\mathrm{r}}-1}{\varepsilon_{\mathrm{r}}+1}\left(0.23+\frac{0.11}{\varepsilon_{\mathrm{r}}}\right) \\
& B=\frac{377 \pi}{2 Z \sqrt{\varepsilon_{\mathrm{r}}}} \text { (A.4) }
\end{aligned}
$$

\section{ACKNOWLEDGEMENTS}

The manuscript is part of the post graduate dissertation carried out at DLRL. Under supervison of D.J. Balasubrahmanyam of SVUEC, Tirupathi and with collaboration of M. Balachary, Sc 'F" of DLRL. Immense thanks is for sharing the laboratory facility of DLRL. Deep acknowledgements are due for these amenities and executive director of SNIST, for his constant encouragement. Last but not least, the teaching and non teaching faculty of SV University deserves for their timely suggestions and sharing of library resources

\section{REFERENCES}

[1] D. M. Pozar, "A Microstrip Antenna Aperture Coupled to a Microstrip Line," Electronics Letters, vol. 21, pp. 49-50, Jan. 1985.

[2] S. D. Targonski and R. B. Waterhouse, "An aperture coupled stacked patch antenna with 50\% bandwidth", IEEE International Symposium on Antenna and Propagation, Baltimore, MD. 1996.

[3] David M. Pozar, "A Review of Aperture Coupled Micro strip Antennas: History, Operation, Development, and Applications", May 1996, on the Web, http://www.ecs.umass.edu/ece/labs/antlab.html

[4] Ramesh Garg, Prakash Bhartia, Inder Bhal, Isac Ittipiboon,"Microstrip Antenna Design Hand Book” Artech House, 2001.

[5] George A.Kyriacou and Anestis A.Marvides, etal "A Design procedure for Aperture Coupled Microstrip Antennas Based on Approximate Equivalent Networks"A technical write up available at www.edatop.com, Last accessed , June 2017.

[6] N.S.Murthy sarma, A.D.sarma and B.R.K.Rao, “ A novel technique of modeling GPS antennas mounted on rocket shaped structure using wedge diffraction analysis” IETE Tech.Rev. Online, March2015 